\title{
Structural response of steel high rise buildings to fire System characteristics and failure mechanisms
}

\section{Gentili, Filippo ; Giuliani, Luisa; Bontempi, Franco}

\section{Published in:}

Journal of Structural Fire Engineering

Publication date:

2013

Link back to DTU Orbit

Citation (APA):

Gentili, F., Giuliani, L., \& Bontempi, F. (2013). Structural response of steel high rise buildings to fire: System characteristics and failure mechanisms. Journal of Structural Fire Engineering, 4(1), 9-26.

\section{General rights}

Copyright and moral rights for the publications made accessible in the public portal are retained by the authors and/or other copyright owners and it is a condition of accessing publications that users recognise and abide by the legal requirements associated with these rights.

- Users may download and print one copy of any publication from the public portal for the purpose of private study or research.

- You may not further distribute the material or use it for any profit-making activity or commercial gain

- You may freely distribute the URL identifying the publication in the public portal

If you believe that this document breaches copyright please contact us providing details, and we will remove access to the work immediately and investigate your claim. 


\title{
Structural response of steel high rise buildings to fire: system characteristics and failure mechanisms
}

\author{
Filippo Gentili ${ }^{1}$, Luisa Giuliani $^{2}$, Franco Bontempi $^{1 \text { ) }}$ \\ 1) School of Civil Engineering, Sapienza University of Rome \\ 2) Department of Civil Engineering, Technical University of Denmark
}

\begin{abstract}
Due to the significant vertical elevation and complexity of the structural system, high rise buildings may suffer from the effects of fire more than other structures.

For this reason, in addition to evacuation strategies and active fire protection, a careful consideration of structural response to fire is also very important.

In this context, it is of interest to investigate the characteristics of the structural system that could possibly reduce local damages or mitigate the progression of failures in case of fire. In this paper, a steel high rise building is taken as case study and the response of the building is investigated up to the crisis of the structure with respect to a standard fire in a lower and in a higher storey: the comparison of the fire induced failures at the different height allows highlighting the role played in the resulting collapse mechanisms by the beam-column stiffness ratio and by the loading condition.
\end{abstract}

Keywords: Structural fire safety; high-rise buildings; collapse mechanisms; hindered thermal expansion; thermal buckling; material degradation.

\section{INTRODUCTION}

In comparison with other structure, high rise buildings can be more endangered by fires as a consequence of their vertical elevation, which not only may hinder a prompt extinguishment of fire and a fast evacuation of peoples, but may also promote a vertical fire spread and a progression of failures, as witnessed by several cases of multi-storey building fires.

The First Interstate Bank fire in Los Angeles in 1998, the Parque Central Tower fire in Caracas in 2004, and The Mandarin Oriental Hotel fire in Beijing in 2009 are three examples of high rise buildings where structural fires developed and involved several floors [1]. Both in the First Interstate Bank and Parque Central Tower, active fire safety systems had been foreseen in the buildings, despite not enforced by the regulations at the time; however sprinklers did not activate, due to faulty maintenance or impaired installation, and the fires spread upwards involving a number of floors and lasting several hours. In the Mandarin Oriental Hotel, a sprinkler system has not yet been installed, since the construction of the building was not complete when a firework hit the structure and triggered the fire. The fire lasted 5 hours and spread downwards from the roof to the bottom of the building. In the last two cases, the fires caused significant damages of the structural system, which however withstood the damages and did not collapse.

The Architecture Faculty Building of Delft in 2009 (concrete), the Windsor Tower of Madrid in 2005 (steel and concrete), and the World Trade Centre (WTC) of New York in 2001 (steel) [2], [3], [4] are instead three examples of buildings, where initial damages caused by the fire triggered a progressive failures of structural elements and resulted in major structural collapses. At least for the last two cases, some structural behaviour patterns have been identified, which could have played an important role in the collapse mechanisms as well as in the standstill or in the propagation of the failures.

Corresponding author: Filippo Gentili, Sapienza University of Rome, School of Civil Engineering, Via Eudossiana 18, 00184 Rome, Italy; Tel.: +39 064458 5224; E-mail: filippo.gentili@uniroma1.it 
In the Winsor Tower [5], an initial loss of vertical load bearing members seems to be responsible of the separation of the first horizontal slab, which impacted on the slab below, causing its failure in turn. The pancake-type progressive collapse [5] seems to have come to a halt in correspondence of two technical floors, which represented a localized stiffening of the system.

In the case of the WTC instead, the progressive collapse could have been initiated by the failure of a horizontal member. According to [6], the presence of stiff columns hindered the thermal expansion of the floors directly heated by the fires and determined their buckling failure. When the fire involves a number of floors, the loss of several horizontal restrains could be responsible of the buckling of the columns at relatively low temperatures and the progression of the collapse to the rest of the structure.

The lessons learned from all above mentioned building fires show that, in addition to other fire safety measures such as evacuation strategies and active fire protection, a careful investigation of the response to fire of the structural system is essential for high rise buildings,. The consequences of a fire-induced collapse are enormous in term of safety of people and integrity of the structure and the risk associated to the event can be significant, even if the occurrence of a structural fire is very low. Therefore, in case active measures cannot prevent the development of a structural fire (such in case of arson or of a fire during a construction stage or a faulty maintenance of the sprinkler system), structural damages should be avoided or limited to a localized area.

Both in the Windsor Tower and in WTC, the organization of the structural system and in particular the ratio of strength and stiffness of adjacent elements seem to have influenced the progressive collapse susceptibility of the system. Another consideration concerning the propagation of failures is offered by the two collapse cases: in the Windsor Tower, a peculiarity of the failure mechanism is represented by the fact that the collapse was limited to a smaller number of floors than those involved in the fire; on the contrary, in the WTC the collapse involved the whole structure, while the fire was limited to a number of floors. It appears clear that a particularly dangerous situation is represented by a possible spread of failures to elements not directly involved in the fire, i.e. element that due to their location or because of greater insulation have still a relatively low temperature at the time of failure.

The aim of this paper is to highlight the above mentioned aspects in the study of the structural response to fire of a high rise building. To this purpose, simplified fire design and verification methods on isolated elements are not sufficient and the response of the structural system as a whole [7] has to be investigated. This is a quite difficult task, which in case of complex structures such as a high rise building [8], necessarily requires some simplifying assumptions in the modelling of the action and of the structure.

In this paper, a steel high rise building is taken as case study and the structural response is investigated with respect to a standard fire in a lower and in a higher storey: the comparison of the fire induced failures at the different heights allows highlighting the role played in the collapse by the beam-column stiffness ratio and a possible propagation of the initial failures to zones of the structure not directly involved in the fire. It has to be pointed out that, as better explained in the following, the interest of this study is focused on the behaviour of the steel components. If this situation can be partly representative of a construction stage on one side, it is of greater interest in order to highlight some basic mechanisms of failure in steel framed structures.

The investigations take into account a full nonlinear response of the structure, influenced by material degradation at high temperatures, possibility of buckling, large displacements and deformations and exploitation of plastic reserve of the elements. Investigations are carried out on substructures, particularly two 3D floor models (FM), which refer to the $5^{\text {th }}$ and $35^{\text {th }}$ storey, and a 3D sectional model (SM) of a vertical frame of the building, where all the stories are represented and a possible vertical propagation of the damages can be evidenced.

In the presentation of the performed investigations and in the discussion of the outcomes, a focus is done on methodological aspects concerning the definition of fire scenarios and collapse criteria, the modelling of the substructures and the identification of failure modalities.

\section{CASE STUDY}

The building considered as case study is a steel high-rise building, whose premises are devoted to offices and residential use. The building has been designed on the basis of the geometry of a building recently built up in Latina, Italy (Fig. 1). The building is composed of 40 storeys and has a framed 
structural system. A vertical bracing system provides stiffness against horizontal actions, while no horizontal bracing system is present within the floor planes, since a bidirectional concrete floor slabs should provide the necessary in-plane stiffness.

The inclusion of hollow spheres in the concrete floor slab, together with the biaxial symmetry of the slabs, allowed for the presence of beams with relatively small profiles spanning long distances

On the contrary, the sections of the columns are quite big, as the resistance against horizontal loads is totally entrusted to the columns. As a result, the difference in the section dimensions of the horizontal and vertical elements is quite high in this type of structural system and becomes particularly significant in the bottom floors, where the column sections are the biggest. This characteristic may influence the structural response in case of fire, as better highlighted in the following.

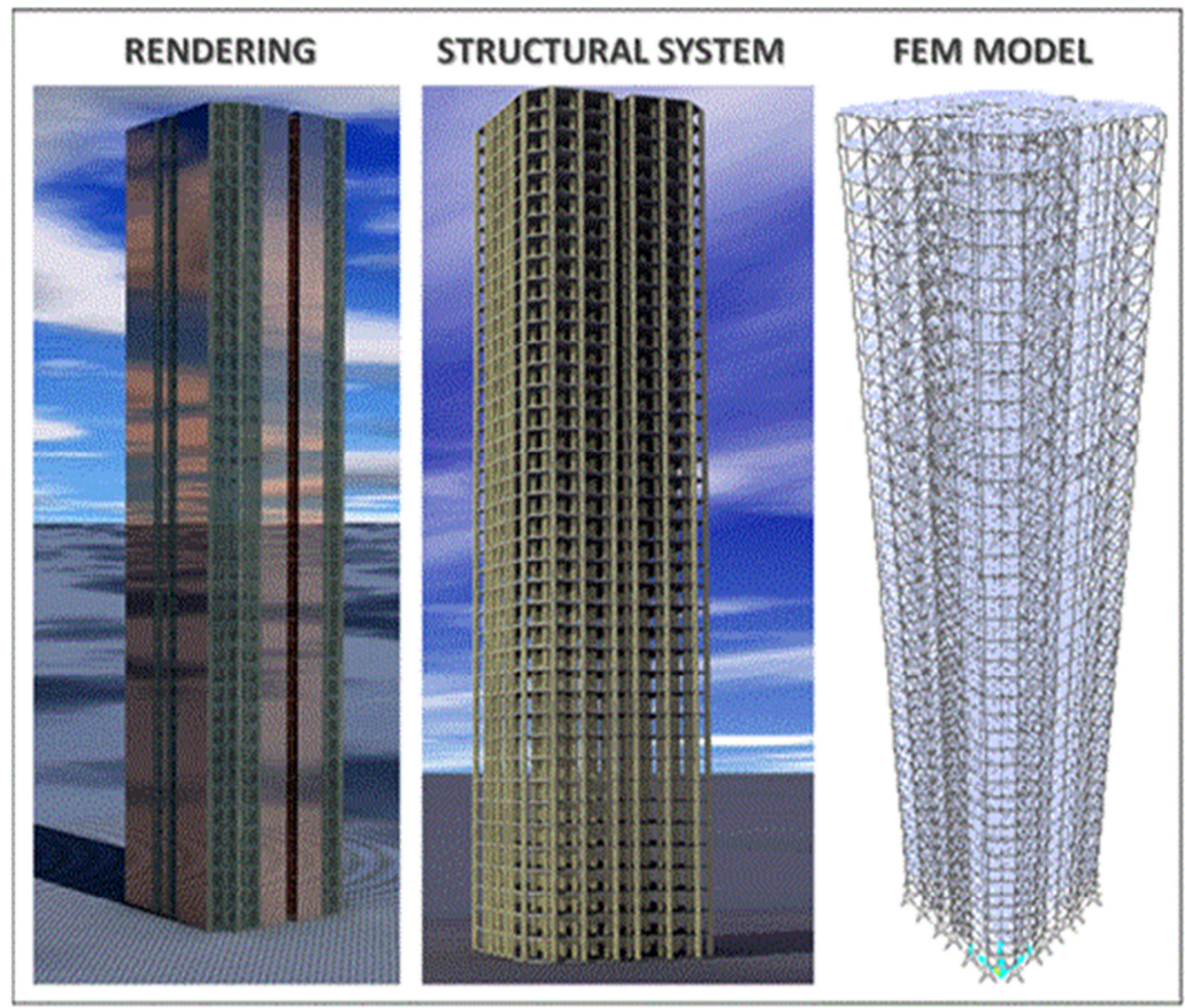

Fig. 1: Rendering and FEM of the investigated high-rise building

\section{Methodology}

When attention is devoted at identifying collapse mechanisms that can possibly be triggered by fire in complex structures, prescriptive rules and simplified design procedures, mostly aimed at preventing the failures on isolated elements, cannot be used. In order to follow the progression of the failures, a more advanced investigation needs to be carried out on the structure, which generally requires the avail of Finite Element Method (FEM) programs and some design experience for modelling both the fire action and the structural response.

The flowchart of Fig. 2 represents the general procedure to be followed in those cases. In the following sections, each step of the flowchart will be described and applied to the case study considered. The most relevant assumptions and modelling aspects will be presented and discussed, with the intention of exemplifying a general methodology for the advanced fire design of complex structures such as a high rise building. 


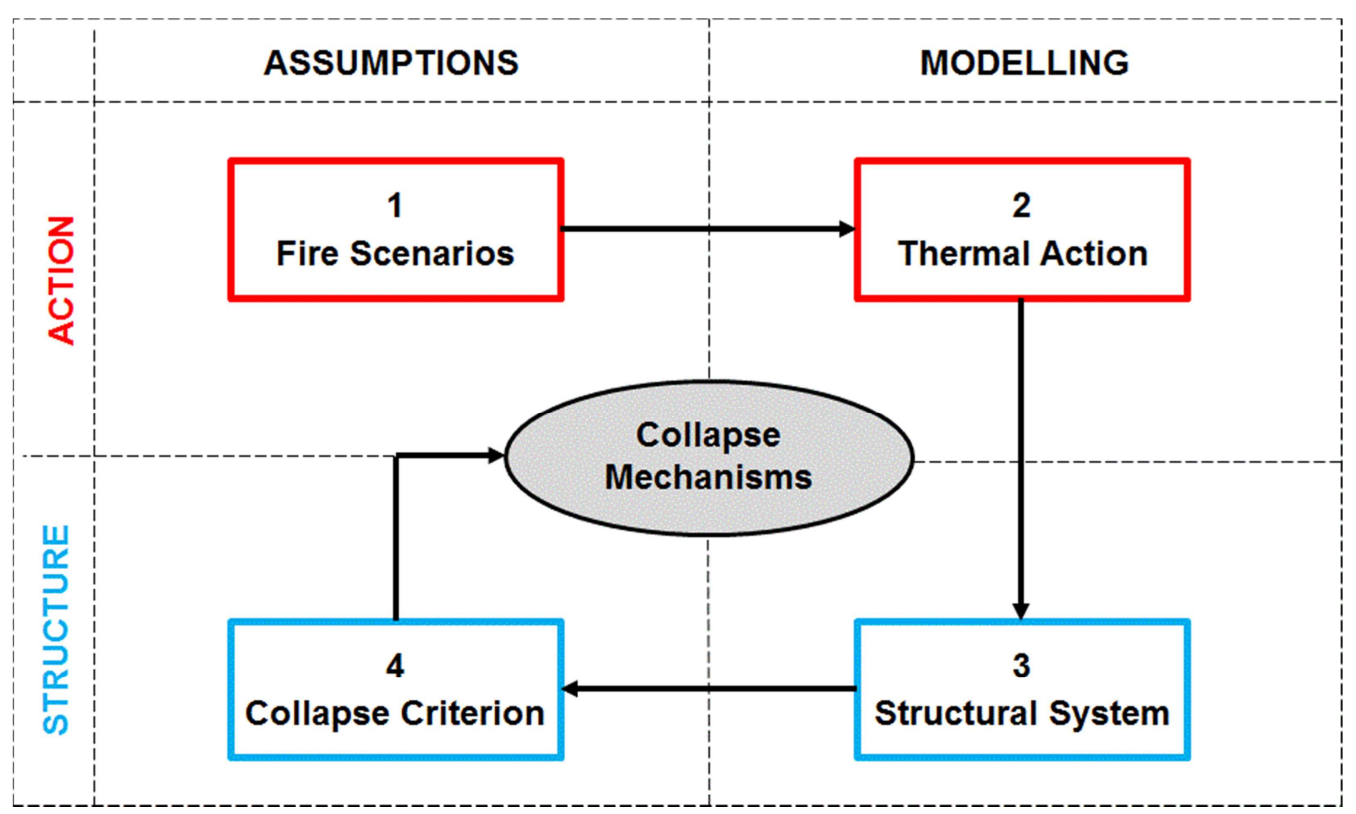

Fig. 2: Procedure for advanced investigation of the response of a complex structure to fire.

\section{Fire scenarios}

The identification of relevant fire scenarios plays a key role for evaluating the response and a possible progressive collapse susceptibility of the structure in case of fire. In literature, the identification of design scenarios is often obtained by means of a risk analysis [9] [10], which is however a relatively onerous procedure. Furthermore, in case of Low Probability - High Consequence (LP-HC) events the risk assessment is complicated by the fact that most probable scenarios are not necessarily the most severe ones in term of consequences and costs.

Therefore, in practice, a number of fire scenarios is often identified on the building [11] on the basis of engineering experience and qualitative considerations or preliminary simplified investigations.

In this study, fire is considered in two different areas of a floor. Furthermore, two reference storeys, specifically the $5^{\text {th }}$ and $35^{\text {th }}$ storey, have been considered for the triggering of the fire. As a result, a set of four different fire scenarios has been investigated on the floor models (Fig. 3). With respect to the sectional model, the fire has been considered to affect either the beams only or both the beams and the columns. In addition to that, a possible loss of vertical compartmentalization has been considered and the fire has been assumed both to be localized within a single storey and to have spread along two subsequent storeys. These assumptions led to the investigations of six additional fire scenarios on the sectional model. All considered fire scenarios highlighted in Fig. 5.

The choice of considering the triggering of the fire at two distinct heights is motivated by the different column profiles present at the bottom and top of the building, which can lead to a different structural response of the steel substructures. The comparison of the outcomes provides an insight of the structural characteristics that play a role in the time and type of failures in a steel framed building and may suggest target modifications for improving the structural performances.

Since the identification of collapse mechanisms is the main interest of this study, the consideration of compartment fires did not seem to be the most appropriate choice, as realistic compartment properties would not be available and damage conditions lower than those assumed would have been required in a realistic design. For this reason the use of a nominal monotonic fire has been preferred to a natural fire model, in order to be able to trace the progression of failures up to the crisis of the building. The use of a conventional fire however could also be preferred for the consideration in the design of unexpected circumstances, which could lead to fires more severe than what expected. Examples of that can be arsons or fires triggered by malevolent explosions or by the impact of a plane. Also less critical events may determine higher element temperatures, such as a refurbishment of the building, which leads to a lower the thermal inertia of the walls or a decrement of the ventilation surfaces, as well as a change of occupancy of the premises, which determines a fuel load increment. 


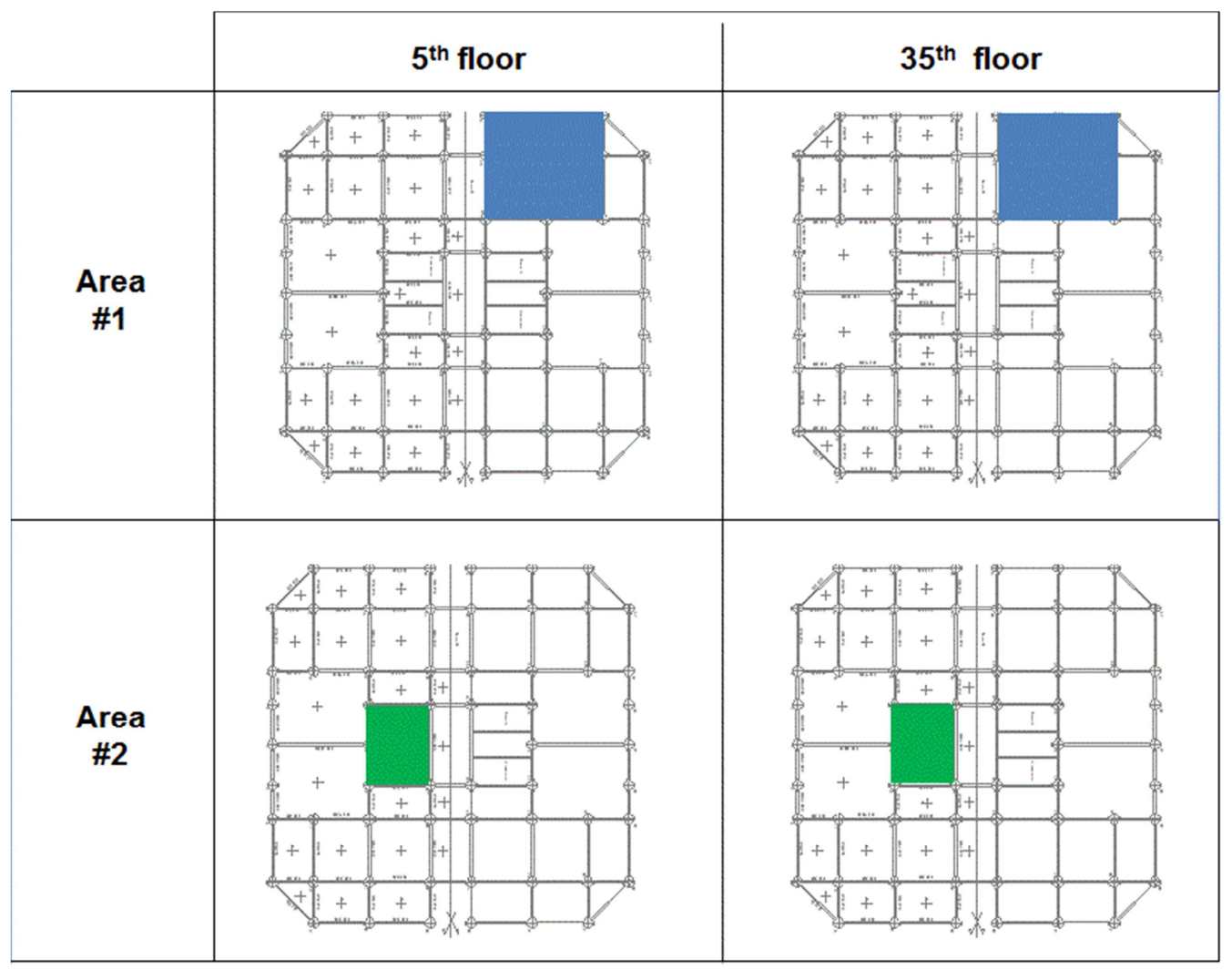

Fig. 3: Fire scenarios considered in the building.

\section{Thermal action}

Once the fire scenarios have been identified, the fire action and the heat transfer to the elements have to be modelled. In the flowchart of Fig. 2 both aspects of fire model and heat transfer model [12] are considered in the $2^{\text {nd }}$ step named "Thermal action". With reference to the fire model, more or less realistic temperature-time curves can be considered for the fire, namely natural or nominal fire curves.

As mentioned above, in the study presented here a nominal fire has been assumed for the sake of simplicity in the form of the standard ISO 834 curve.

The heating curves of steel members have been calculated under the assumption of uniform temperature along the sections, according to the Eurocode formula for the heating of uninsulated steel profiles steel [13] and using a convective coefficient $\alpha=25 \mathrm{~W} /\left(\mathrm{m}^{2} \cdot \mathrm{K}\right)$ and a total emissivity $\varepsilon=0.5$ (the shadow effect of the profiles is neglected on the safe side). The resulting temperatures have been applied as thermal load to all nodes of the elements in the tributary area of the fire scenario considered in each investigation.

\section{Structural system}

Modelling in detail such a big and complex structure can be quite onerous in term of analysis time, but also in term of difficulties in the interpretation of results, which is the main goal of each investigation: in order to understand properly the structural behaviour and also be able to check the validity of the outcomes, it's important to simplify the models as much as possible, provided that aspects that are of interest in the structural response will be duly represented.

In this respect, a central point of fire-induced investigations concerns the identification of a possible spread of the local damages from the heated members to elements not directly involved in the fire. In a 3D building, the collapse propagation can occur both within the floor plan where the fire has triggered and along the building elevation. Two different type of substructures have therefore been considered (Fig. 4): i) a floor model, where the direct effect of fire on heated beams can be evaluated (vulnerability to fire) and then the consequence of a possible failure of the heated beams on the rest of the floor system can be investigated (structural robustness of the system); and ii) a sectional model, where a possible overloading and collapse of the columns consequent to beam failure can be identified and a vertical propagation of the collapse can be identified. Here the term vulnerability is intended as 
sensibility to accidental actions [14] and the term robustness is referred to the sensibility to local failures [5]. Concerning the floor substructure, it is important to point out that the floor slabs have not been modelled, since, as mentioned before, this study is mostly aimed at highlighting the role of the steel components in the failure mechanisms of framed tall structural systems. Concerning the sectional substructure, a spatial model has been implemented, capable of highlighting possible out of plane displacements of the elements,. In order to simulate the presence of beams perpendicular to the frame, transversal restraints have been applied to the sectional model in the $3^{\text {rd }}$ dimension.

A commercial finite element code has been used for the investigations [15], which takes into account thermo-plastic material and geometric nonlinearities. Either the sectional and the floor models have been implemented by using beam elements, which has been properly meshed in order to have sufficient accuracy in: i) the application of thermal loads; ii) the calculation of displacements and forces; iii) the representation of the deformed shape and other output variables. With respect to the application of the thermal loads in particular, a sensitivity analysis of the displacement to the mesh size has been performed, which has led to the choice of an optimal discretization of the elements. Dead and live loads have been applied as line loads along the axis of the beams and considered together with the self-weight in a first load step. In a second load step the heating curves calculated for the steel profiles have been applied to the nodes of the elements pertinent to the area of the fire scenario considered, while other elements have been assumed to remain cold throughout the investigation. An explicit dynamic solver has been used in order to overcome convergence problems due to the formation of local mechanisms, thus enabling to trace down the propagation of failures.

\begin{tabular}{|c|c|c|c|}
\hline & Floor Model \\
Single Storey & Sectional Model \\
All Storeys
\end{tabular}

Fig. 4: Different models considered for the investigations

\section{Collapse condition}

The last step of the investigation procedure concerns the interpretation of the results and the identification of collapse modes and collapse conditions for each fire scenario. For this purpose, a collapse criterion has to be chosen on the basis of the safety objectives defined for the structures. As explained in the first paragraph, the investigations presented here have two main different goals: it is 
of interest either i) to identify the time and type of failures, and ii) to outline a possible propagation of the collapse.

To the first aim, a limit on the displacement of significant points of the structure can be used and calibrated on the basis of the performance required to the structure. If the functionality of the structure should be maintained, a collapse condition, which is representative of the failure of one element, is the runaway of a significant point of the structure, with this term meaning the accelerating and irreversible downward displacement of the considered point [6]. Conventional limit values for the maximum displacement of members are also found in literature and regulations with respect to steel elements in bending [16] [17]. In the discussion of the results, the displacement limit indicated in Eq.1b will be considered and compared with the runaway criterion, as identifiable from the qualitative observation of the monitored displacements.

To the second aim, the collapse condition is represented by a well-identifiable circumstance, namely the failure of elements not directly involved in the fire, which are assumed to remain cold in the investigations performed.

\section{Main results}

The most relevant results of the analyses are presented and discussed in the following. These results refer to both the floor (behaviour of beams) and the sectional model (behaviour of beams and columns). An overview of the investigations performed is given in Fig. 5.

FLOOR MODEL

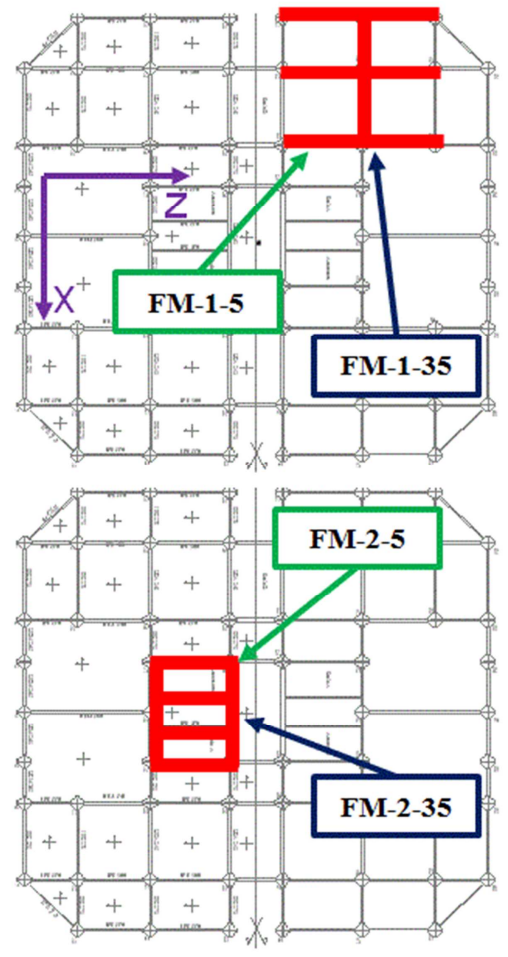

SECTIONAL MODEL

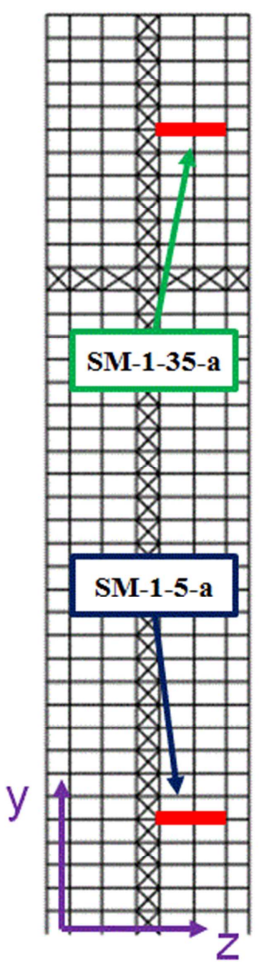

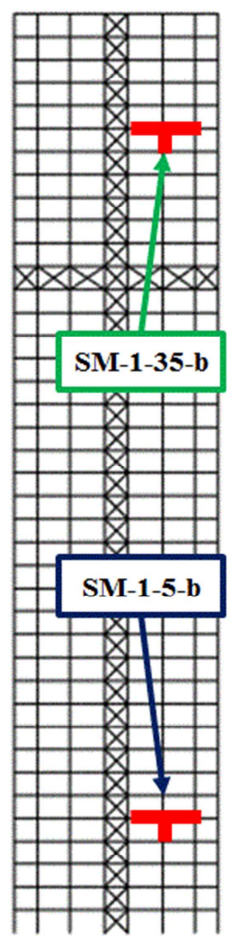

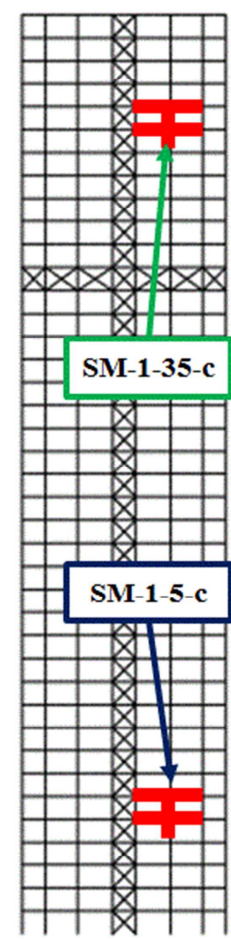

Fig. 5: Overview of models and scenarios considered and summary of the investigation performed

The abbreviations used for identifying the different investigations are formed by a set of two letters followed by two numbers separated by a dash, and have the following meaning:

- the first two letters of the abbreviation refer to the model studied (FM and SM stays for sectional model and floor model respectively);

- the first number refers to the area of the floor where the fire is assumed (scenario 1 or scenario 2 )

- the second number refer to the story number ( $5^{\text {th }}$ or $35^{\text {th }}$ storey);

- in the investigation on the sectional model, a last letter is specified too, which refers to the extension of the fire; specifically the letter:

a indicates that the fire has been considered in a single floor and only on beam elements; 
b indicates that fire is limited to a single floor but affects the beams and the related column;

c indicates that the fire is assumed to have spread upwards and the beams and columns of two consecutive floors have been considered to be affected by the fire.

\section{Floor model - Scenario 1 - Fire on beams of only one floor (FM-1-5 \& FM-1-35)}

The results of the analysis on the first scenario for the $5^{\text {th }}$ floor highlight the following sequence of failures in the area involved in the fire (Fig. 6):

1. After 2 min of fire, an out of plane buckling mechanism triggers, involving three beams that converge in the middle external column (i.e. the two external transversal beams, beam 18 and beam 32 , and the longitudinal beam between them, beam 25). Almost contemporarily, the most internal beam on the left (beam 34) buckles out of plane too. The early failure of those beams is only due to the eigenstresses induced by the hindered thermal expansion of the beams, consequent to the strong column - slender beam frame type: specifically, all four beams have an IPE270 profile, while the columns adjacent to them have HEM1000* profiles. As a consequence, the beam failures trigger when the temperatures are still very low (around $100^{\circ} \mathrm{C}$ ) and the degradation of the mechanical properties, which typically plays a determinant role in fire-induced collapses, has not occurred yet.

2. Shortly after the first four beams, the two transversal beams in the middle (beam 33 and beam 19), buckle out of plane too. The slightly higher resistance of these beams in comparison to the previous one can be imputed to the bigger sections of these beams, which have an IPE300 profile.

3. At about 10 and 15 minutes of fire respectively, also the last two beams directly involved in the fire (beam 34 and beam 26) buckle out of plane. The higher resistance of those beams is due to the different profile of the sections, which is a HEA240.

4. At this point the temperatures are quite high $\left(\mathrm{ca} .600^{\circ} \mathrm{C}\right)$ and the internal beams, which carry higher load than the external ones, experience a vertical runaway and exceed the maximum acceptable displacement considered as nominal collapse criterion (Eq.1b). The material degradation is responsible for the runaway and determines the overcoming of the collapse condition.
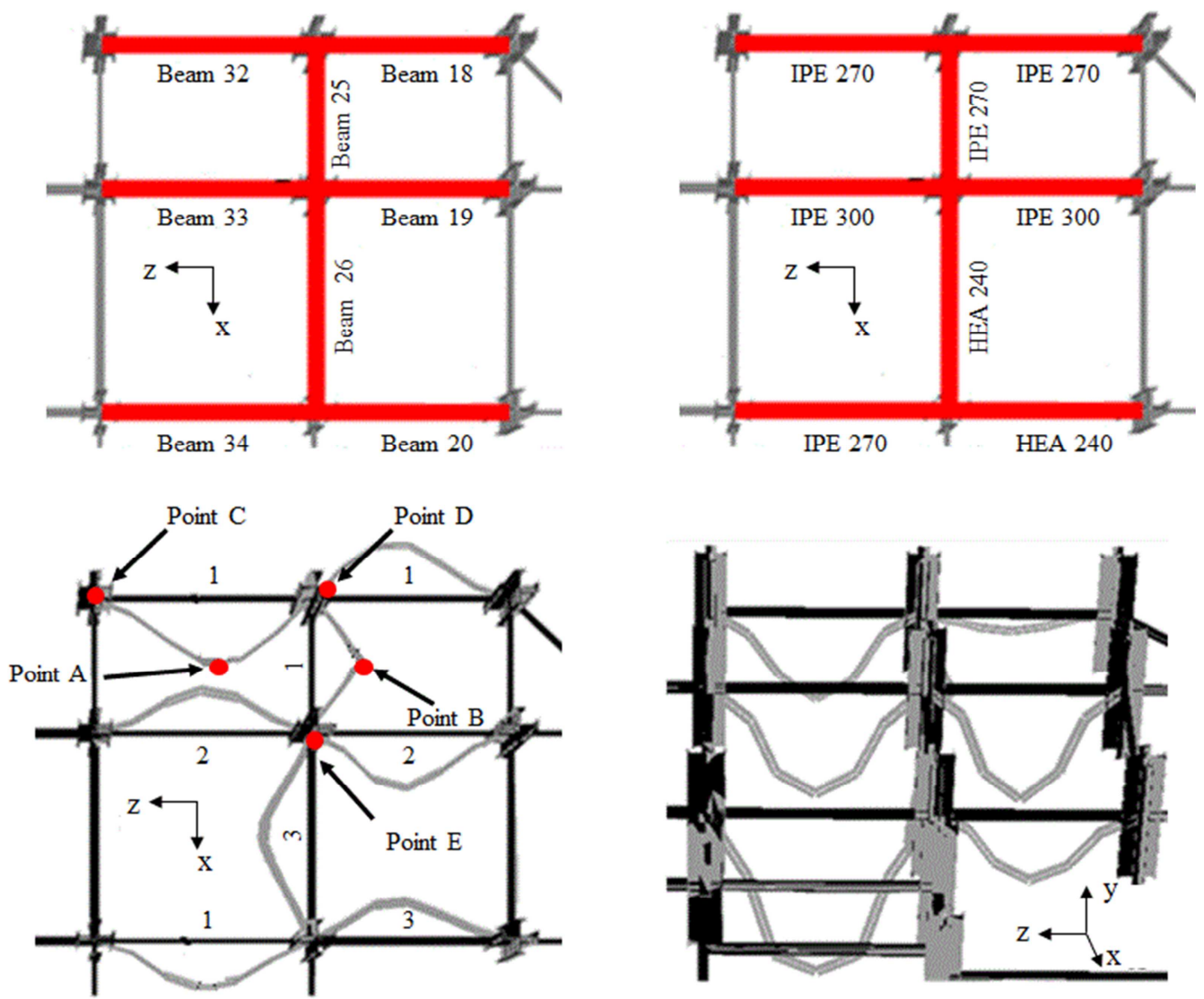

Fig. 6: Fire scenario 1 for the $5^{\text {th }}$ floor: section of heated elements (top left), progression of collapse (top right), deformed configuration after $14 \mathrm{~min}$ (bottom left) and after $20 \mathrm{~min}$ (bottom right). 
The results of the investigations carried out at the $5^{\text {th }}$ floor are represented in Fig. 6 in term of deformed configurations and in Fig. 7 in term of displacements vs. temperature and of axial force vs. temperature curves. In the first row of Fig. 6 the name (left) and the sections (right) of heated elements are reported. The second row of Fig. 6 shows on the left the deformed configurations at $14 \mathrm{~min}$. Here the progression of beam failures is indicated by numbers from 1 to 4 , which correspond to the steps illustrated above; on the right instead the deformed configuration at $20 \mathrm{~min}$ of fire is reported, where the in-plane buckling of beams is visible and significant vertical displacements of beams can be observed.

It seems relevant to highlight the fact that the same design characteristic that is responsible for the early failure of the beams, i.e. the strong column - slender beam system, ensures on the other side a compartmentalization of the collapsing sections of the structure and avoid the propagation of the collapse to the vertical elements, which are only slightly overloaded by the stress redistribution consequent to the beam failures and therefore could hardly be involved in the collapse mechanism.
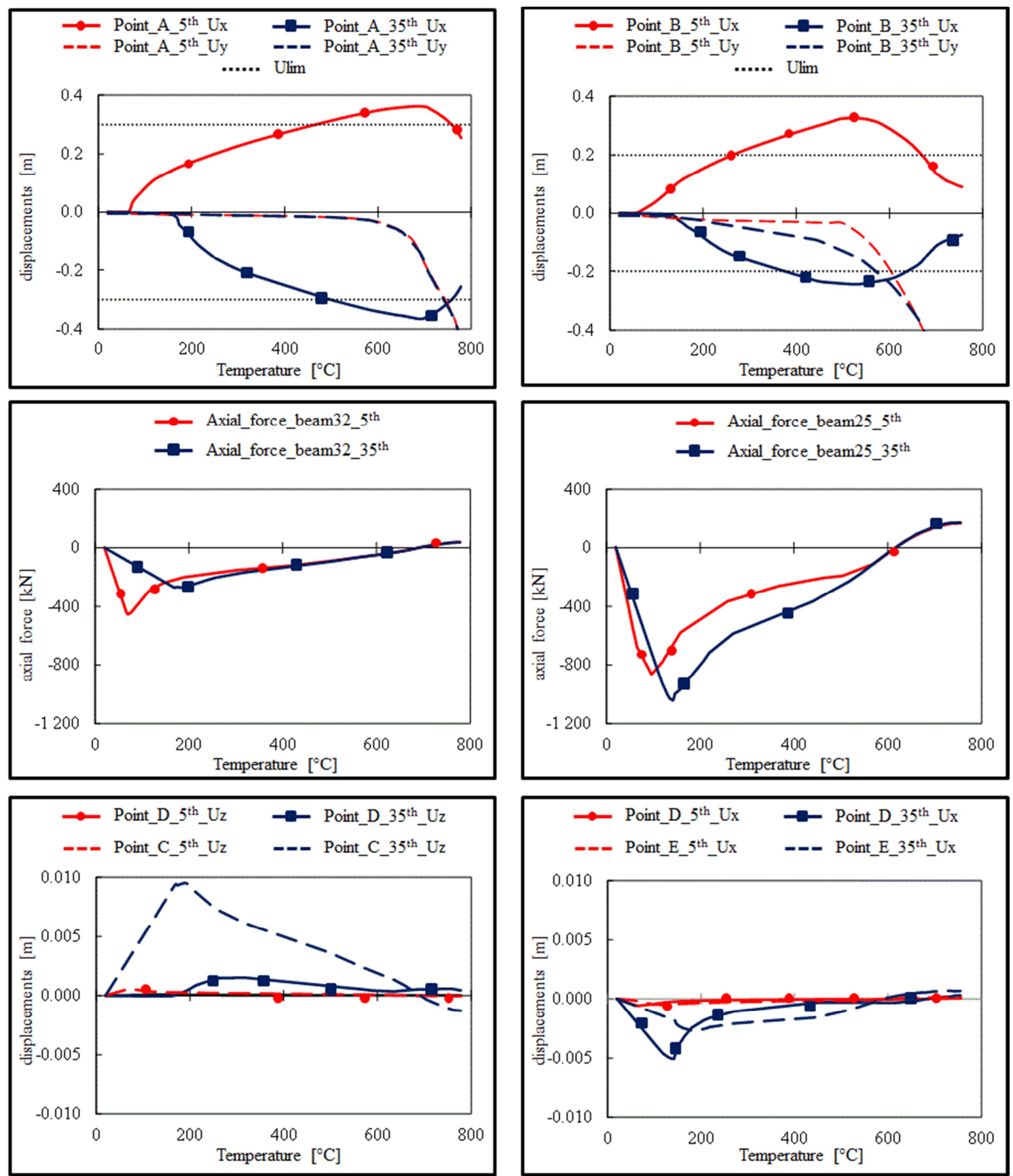

Fig. 7: Results of fire scenario 1, in term displacement of beams mid-span (first row), forces of the beam (second row) and displacement of the columns adjacent to the monitored beam (third row). 
The results of the investigation carried out at the $35^{\text {th }}$ floor are reported in Fig. 7 in term of displacement vs. temperature (first row) and axial force vs. temperature (second row). From the observation of the displacements, it can be seen that the collapse mechanism at the $35^{\text {th }}$ floor is similar to that one at the $5^{\text {th }}$ floor, but it is slightly delayed.

This delay can be entirely ascribed to the different column profiles present at the $35^{\text {th }}$ floor (HEM400), which offer less resistance to the thermal expansion beams: this is confirmed by the fact that the columns at the $35^{\text {th }}$ floor are slightly displaced by the thrust of the beam, contrarily to what happen to the column at the $5^{\text {th }}$ floor (third row of Fig. 7).

\section{Floor model - Scenario 2 - Fire in one storey on beams (FM-2-5 \& FM-2-35)}

The outcomes for fire scenario 2 are shown with respect to a fire at the $5^{\text {th }}$ floor and a fire at the $35^{\text {th }}$ floor in term of deformed configurations (Fig. 8) and of trend of displacement and axial force of members (Fig. 9).

At both the $5^{\text {th }}$ and $35^{\text {th }}$ floor a buckling mechanism occurs, which involves three of the heated beams and specifically beam 65 (whose mid-span is referred to as point F in Fig. 8), beam 68 and beam 58 .

As occurred for fire scenario 1 , the mechanism at the $35^{\text {th }}$ floor is delayed with respect to the mechanism at the $5^{\text {th }}$ floor. However in fire scenario 2, the buckling mechanism is different for the two floors: the beams at the $5^{\text {th }}$ floor buckle out of the plane, while the same beams at the $35^{\text {th }}$ floor have time for developing a significant vertical displacement before failing and the buckle occurs therefore along the vertical direction. Furthermore, a propagation of the failures of two beams not directly involved in the fire and specifically of beam 57 and beam 59 (whose mid-span is reported as point $\mathrm{G}$ in Fig. 8) can be evidenced at $35^{\text {th }}$ floor. This mechanism is observable in the right bottom part of Fig. 8.

The higher buckling resistance at the $35^{\text {th }}$ floor is again a consequence of the lower horizontal restrain provided by the tapering of the column profiles along the building height. However in this scenario this characteristic of the system leads to the occurrence of a different and less local buckling mechanism, which involves all heated beams and 2 beams that fall outside the fire scenario as well.
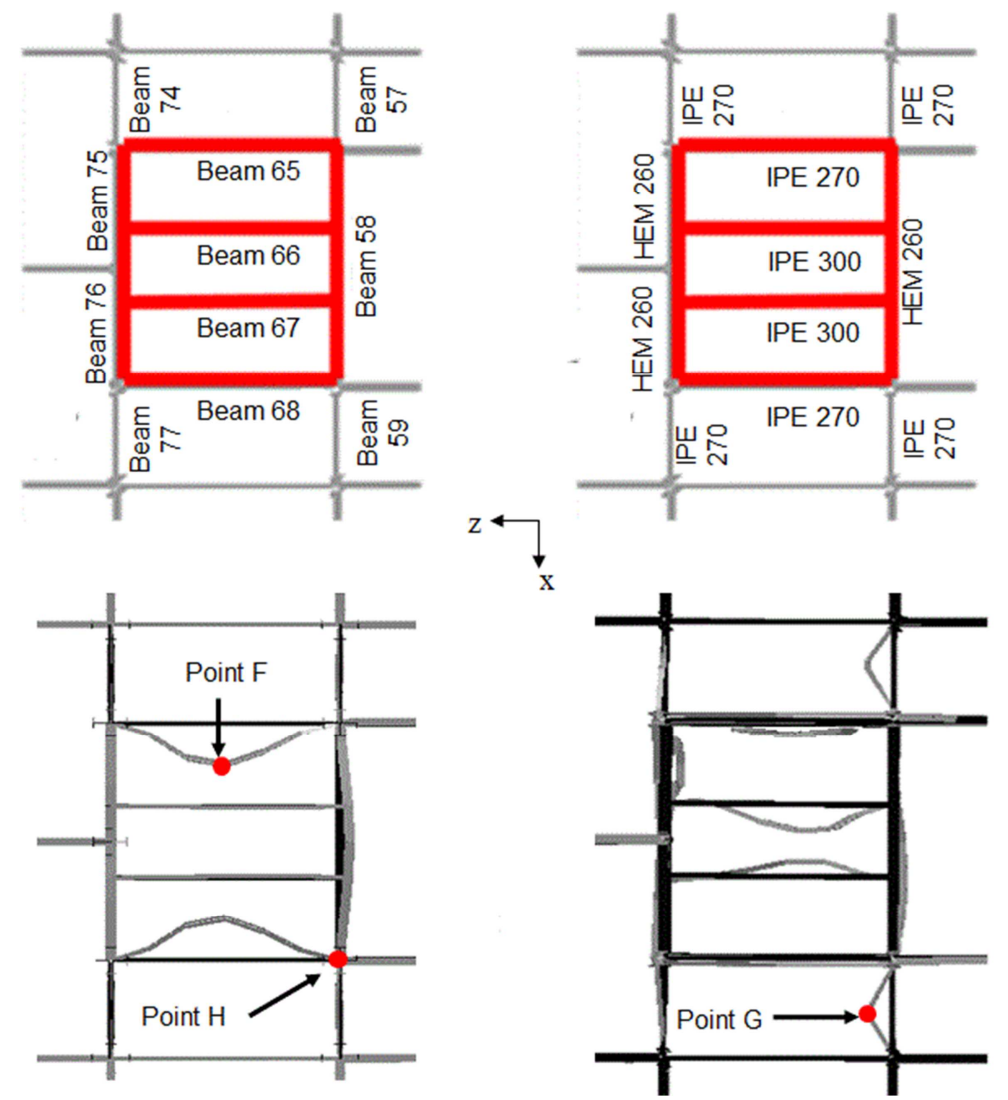

Fig. 8: Deformed shape of the $5^{\text {th }}$ floor (left column) and of the $35^{\text {th }}$ floor (right column) in case of fire scenario 2. 
It has been previously said that a high vulnerability of the system could be ascribed to the very stiff columns (as at the $5^{\text {th }}$ floor), which led to an early buckling mechanism due to the highly constrained thermal expansion of the beams; the presence of slender columns (as at the $35^{\text {th }}$ floor) may lead instead to a delayed buckling and have therefore a positive effect on the overall resistance. Nevertheless, this example highlight that this delayed failure can also be detrimental, as the higher resistance of the beams to a local buckling determines the triggering of a larger buckling mechanism, which involves also elements not directly affected by the fire.
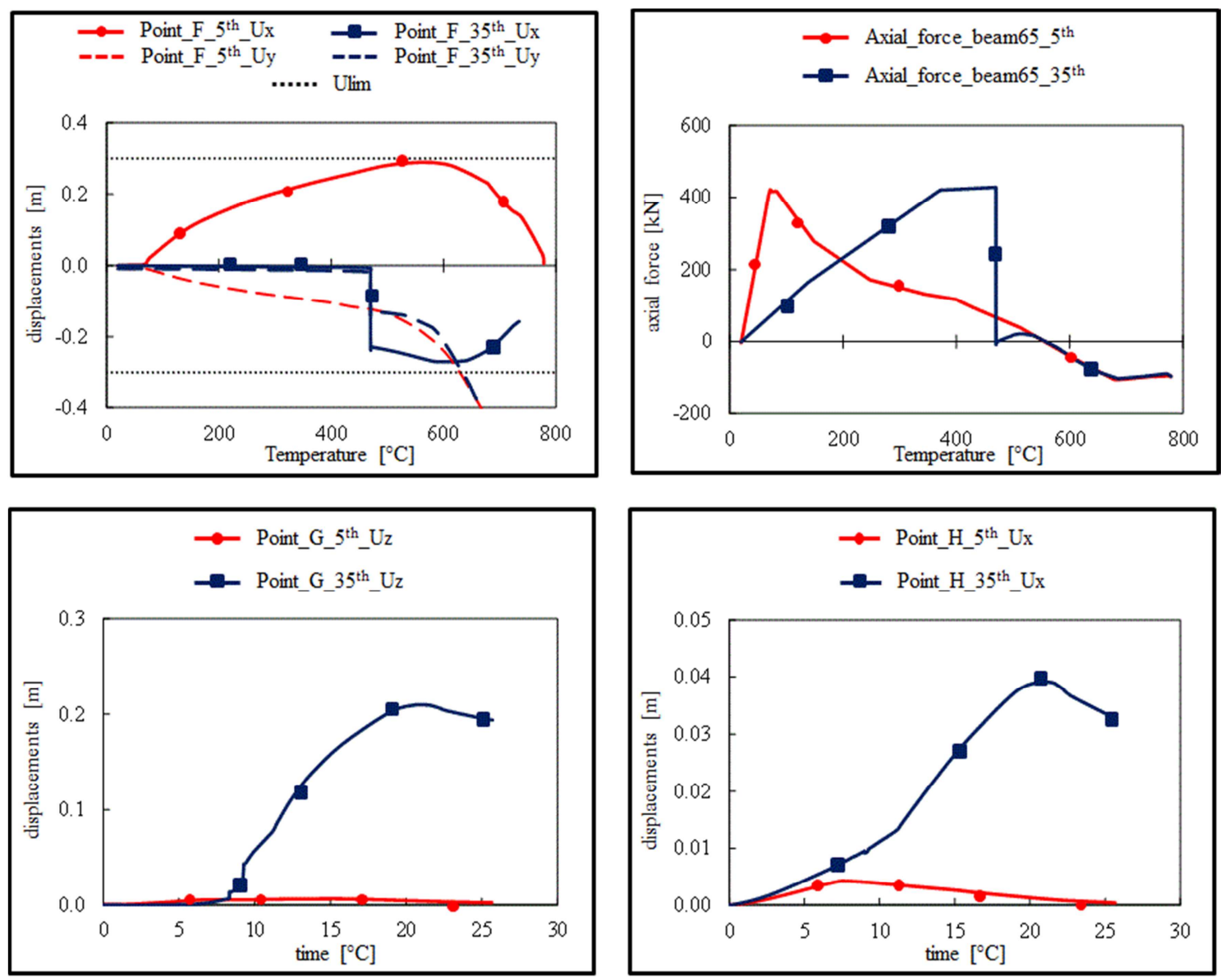

Fig. 9: Results of scenario 2: displacements of point F, representing the mid-span of beam 65 (top left) and in term of axial force of beam 65 (top right); outwards displacements of point $G$, representing the mid-span of the cold beam (bottom left) and of point $H$, which gives indication on the restrain provided to the beam by the adjacent column.

\section{Sectional model - Scenario 1 - One storey fire on beams (SM-1-5-a \& SM-1-35-a)}

In this investigation the sectional model of the building is considered and the fire is assumed to heat only the beams pertinent to the area considered for the fire scenario 1 . The results of the sectional model are consistent with those obtained by the investigation of scenario 1 in the floor model (FM-15) and are characterized by an early failure of the heated beams, which buckle out of plane just after few minutes of fire.

At the $5^{\text {th }}$ floor, as evidenced also in the floor model, the failure of the heated beams occurs at relatively low temperatures and is almost exclusively due to hindered thermal expansion, since the material degradation has not become significant at those temperatures.

It seems relevant to highlight the fact that the very early beam failure prevents the redistribution of high stresses on the columns; therefore, the high vulnerability to fire of horizontal elements is accompanied by a robust behaviour of the vertical load carrying system. When the horizontal restrain provided by the beam is lost, the buckling length suddenly increases, possibly leading to the column failure [6]. In this specific case however, a possible buckling of the vertical elements doesn't seem a concern, due to the low loading condition and the very high stiffness of the column at the $5^{\text {th }}$ floor. 
In Fig. 10 the differences between the displacements at the $5^{\text {th }}$ and $35^{\text {th }}$ floor of the mid-span of a heated beam are reported and a delay in the out-of-plane buckling of the beam at the $35^{\text {th }}$ floor with respect to the beam at the $5^{\text {th }}$ floor is observable. This type of crisis remains however a local phenomenon, as it involves exclusively the heated elements and is limited to an area of about $100 \mathrm{~m}^{2}$, which represent around the $8 \%$ of the whole floor area. It may be interesting to compare this value with the limit of $15 \%$ (corresponding to $180 \mathrm{~m}^{2}$ in this case) indicated by the old US guidelines [18] for defining a local collapse in case of accidental failure of a column.
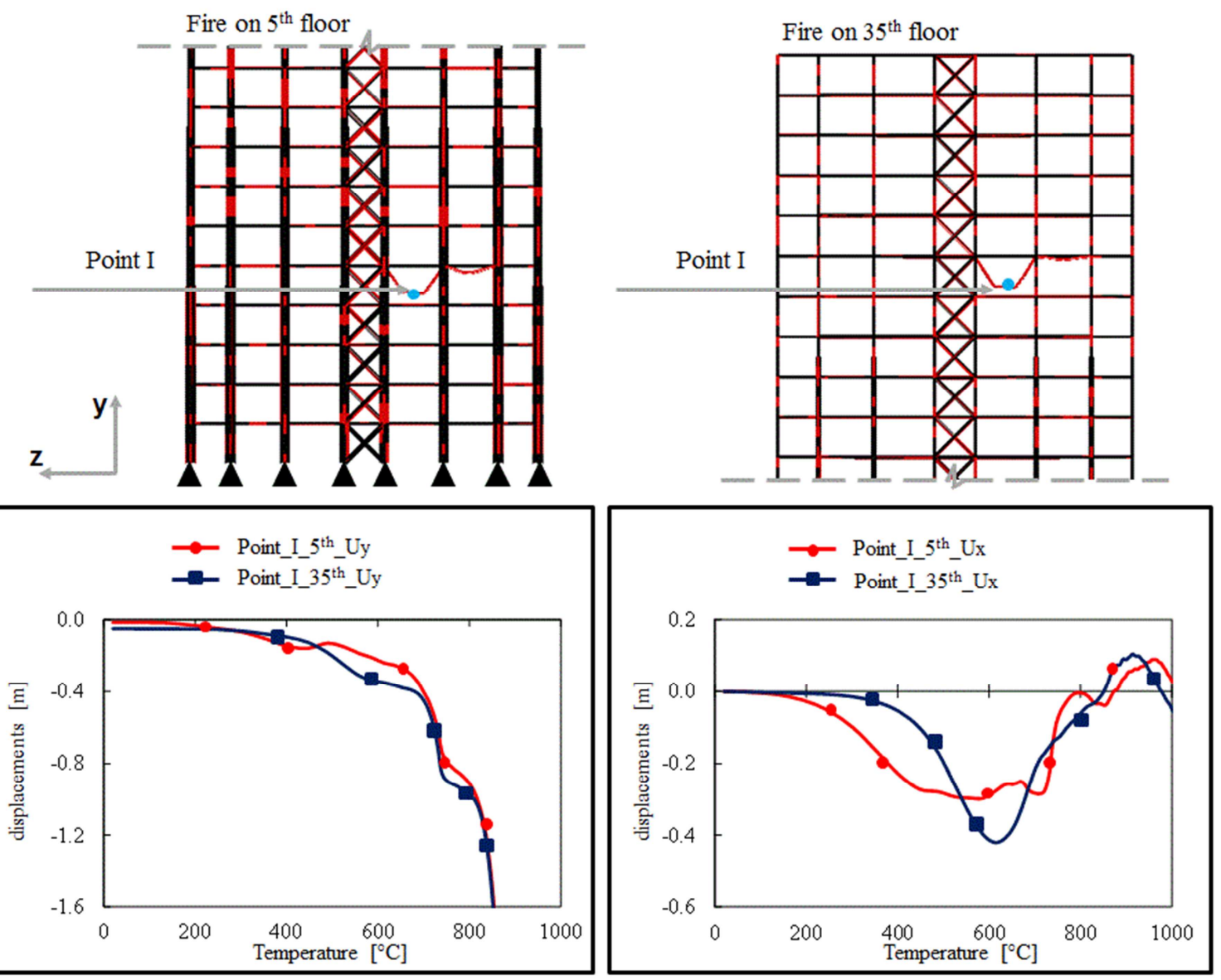

Fig. 10: Results of SM-1-5-a and SM-1-35-a: vertical (bottom left) and out of plane (bottom right) displacement of the mid-span of a heated beam (point $I$ ) at the $5^{\text {th }}$ (top left) and $35^{\text {th }}$ floor (top right).

\section{Sectional model - Scenario 1 - One storey fire on beams and columns (SM-1-5-b \& SM-1-35-b)}

In this section the outcomes of the investigation performed on the sectional model are presented with respect to a fire affecting both horizontal and vertical elements pertinent to the area of scenario 1 . The fire is considered to be localized within one storey, first at the $5^{\text {th }}$ floor and then at the $35^{\text {th }}$ floor. The consideration of the fire on the columns allows highlighting some differences in the evolution of collapse with respect to the previous case, where only beams were considered to be heated by the fire.

The results of the investigations are reported in Fig. 11 in the first row the deformed configurations of the structure at $90 \mathrm{~min}$ of fire are represented for both the case of a fire at the $5^{\text {th }}$ floor (left column) and at the $35^{\text {th }}$ floor (right column), while in the second and third rows the displacements of some significant points are shown in the two cases.

At the $35^{\text {th }}$ floor the column experiences a crisis when the critical temperature (around $800^{\circ} \mathrm{C}$ ) is reached after $45 \mathrm{~min}$ of fire. In correspondence of these values, the displacement of mid-point of column (indicated with point L in Fig. 11) increases greatly. The crisis occurs because the plastic limit is achieved, as observable in the top left graph of Fig. 11.

The collapse occurs at very high temperatures, due to the combination of a low initial value and a low increment of axial forces. 
With respect to the first aspect, the low load to resistance ratio of the column can be only partly ascribed to the fact that the column segment considered is just below the tapering of the profile. A more significant consideration concerns the low loading conditions that are assumed in case of fire. In this respect, it has to be highlighted that the building has been designed in compliance with the load combination (Eq. 2a) for the Ultimate Limit States (ULS), where wind, seism, snow and service loads have been considered as variable actions. The coefficients for permanent and live loads are compliant to those indicated in the Italian regulations: in particular, the most severe combination for the dimensioning of the columns is the one where wind is considered as leading variable action and in this case a safety factor $\gamma_{\mathrm{Q} 1}=1.5$ is foreseen by the code [19].

A different combination (Eq. 2b) has to be considered instead in case of fire, where loads are strongly reduced [20] and in particular almost permanent values of variable actions are assumed. This results in neglecting the presence of wind for fire design, since the coefficient $\psi_{2 i}$ associated to the wind action is 0 in the above mentioned code.

a) ULS: $\quad \gamma_{\mathrm{G} 1} \cdot \mathrm{G}_{1}+\gamma_{\mathrm{G} 2} \cdot \mathrm{G}_{2}+\gamma_{\mathrm{P}} \cdot \mathrm{P}+\gamma_{\mathrm{Q} 1} \cdot \mathrm{Q}_{\mathrm{k} 1}+\Sigma_{\mathrm{i}=2, . \mathrm{n}}\left(\gamma_{\mathrm{Q} \mathrm{i}} \cdot \psi_{0 \mathrm{i}} \cdot \mathrm{Q}_{\mathrm{ki}}\right)$

b) ALS: $\quad \mathrm{G}_{1}+\mathrm{G}_{2}+\mathrm{P}+\mathrm{A}_{\mathrm{d}}+\sum_{\mathrm{i}=1, \ldots \mathrm{n}}\left(\psi_{2 \mathrm{i}} \cdot \mathrm{Q}_{\mathrm{ki}}\right)$

where symbols have the following meaning:

$\mathrm{G}_{1}$ : $\quad$ permanent loads of all structural elements

$\mathrm{G}_{2}$ : $\quad$ permanent load of all non-structural elements

$\mathrm{P}$ : $\quad$ prestressing loads

$\mathrm{Q}_{\mathrm{k} 1}$ : $\quad$ characteristic value of the leading variable action

$\mathrm{Q}_{\mathrm{ki}}$ : $\quad$ characteristic value of the accompanying variable action

$\gamma_{\mathrm{G} 1}: \quad$ partial safety factor for structural permanent loads

$\gamma_{\mathrm{G} 2}: \quad$ partial safety factor for non-structural permanent loads

$\gamma_{\mathrm{Qi}}: \quad$ partial safety factor for live loads

$\psi_{0 \mathrm{i}}: \quad$ combination factor for the rare value of actions

$\mathrm{A}_{\mathrm{d}}$ : $\quad$ exceptional action

$\psi_{2 i}$ : combination factor for the almost permanent value of actions

As a result, the columns have a quite low load-resistance ratio, which is consistent with the high distance between the starting points of the curves representing the axial force and the yielding condition, which are shown in Fig. 11.

With respect to the second aspect, a very low inclination of the curve representing the axial force is visible in Fig. 11, which can be ascribed to the very low constraint provided by the slender beam to the thermal expansion of the column. This is the main reason why the resistance of the column to fire is much greater that the resistance of the beam system.

The resistance of the column is of course a central aspect in the structural response of a high-rise building to fire, since a crisis of the columns could lead to a disproportionate collapse involving the upper floors. The displacements of the top of the building, specifically the horizontal displacement at the top of the last external column (point $\mathrm{N}$ ) and the vertical displacement at the top of the last column directly above the heated one (point $\mathrm{M}$ ) are reported at the bottom of Fig. 11. These displacements can be takes as indices of the crisis of the whole structure, consequent to the buckling of the heated column, which is instead visible by observing the horizontal displacement of the mid-span of the column (point L) reported in the top part of Fig. 11.

The results discussed above refer to the case of a fire at the $35^{\text {th }}$ floor. In case the fire is assumed at the $5^{\text {th }}$ floor, the considerations concerning the low increment of the axial force in the column are still valid. However a crisis of the column at the $5^{\text {th }}$ floor cannot be evidenced, since the bigger profiles of the columns ensure a greater buckling resistance with respect to the $35^{\text {th }}$ floor. Therefore, while a fire at $35^{\text {th }}$ floor causes the runaway of the head of the external column (point $\mathrm{N}-35^{\text {th }}$ ) after about 90 minutes, this is not the case if the fire triggers at the $5^{\text {th }}$ floor (point $\mathrm{N}-5^{\text {th }}$ ). 

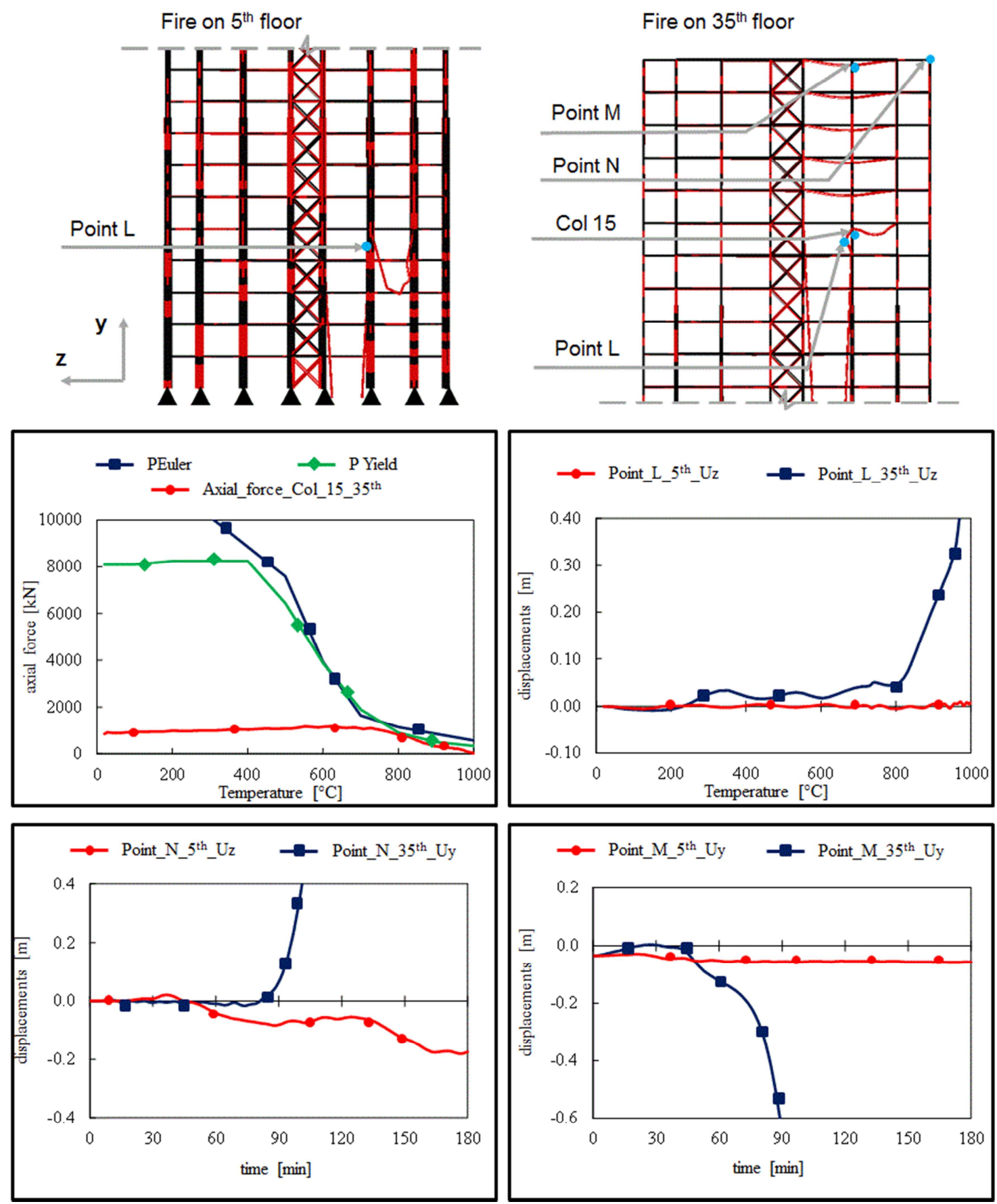

Fig. 11: Results of SM-1-5-b and SM-1-35-b: deformed configurations after 90 min of fire at the $5^{\text {th }}$ (top left) and $35^{\text {th }}$ floor (top right); evolution of the axial force in the heated column (column 15) and yield crisis (centre left); displacements of the mid-span of the heated column (point $L$ ) at the $5^{\text {th }}$ and $35^{\text {th }}$ floor

(centre right); horizontal displacement (bottom left) of the top of the external column (point $N$ ) and vertical displacement (bottom right) of the top node of the heated column (point $\mathrm{M}$ )

\section{Sectional model, Scenario 1, Two storeys fire on beams and columns (SM-1-5-c \& SM-1-35-c)}

As mentioned above, a particular dangerous situation for high-rise building is represented by the fire spread on a number of adjacent storeys, as a consequence of external fire propagation throughout windows or ducts or of the loss of vertical compartmentalization in the building.

This situation has been contemplated by assuming that the fire heats both horizontal and vertical elements pertinent to the area of fire scenario 1on two adjacent floors and at two different heights in the buildings, namely the $5^{\text {th }}$ and $6^{\text {th }}$ floor, as well as the $35^{\text {th }}$ and $36^{\text {th }}$ floor. Both in case a lower or higher height is assumed for the triggering of the fire, the first failures are represented by the crisis of 
the beams, which fail out of buckling in both cases. As a consequence, the heated column adjacent to the failed beams loose horizontal restrains in two points, with a considerable increment of the column buckling length.

In case of a fire at the $35^{\text {th }}$ and $36^{\text {th }}$ floor, a change in the failure mode of the column occurs and the column becomes slender as a consequence of the increased buckling length: the column is designed to have a plastic failure and, when the designed buckling length is preserved, the yielding resistance stays always under the Euler buckling load, as visible in the top left graph of in, which refers to the same column profile; when two horizontal restrained are lost however, the limit of the Euler buckling drops under the yielding limit, as observable in the graph on the left of Fig. 12. For what above said, the axial force in the column does not increase significantly; therefore this abrupt drop in the resistance doesn't determine an immediate buckling failure of the column, which resists up to about $650^{\circ} \mathrm{C}$ before failing and triggering the collapse of the upper part of the building. As expected, the behaviour of the structure in case of a fire in two adjacent storeys is worse either in term of critical temperature and in term of resistance time than in case the fire is limited to one floor only (SM-1-35-b).
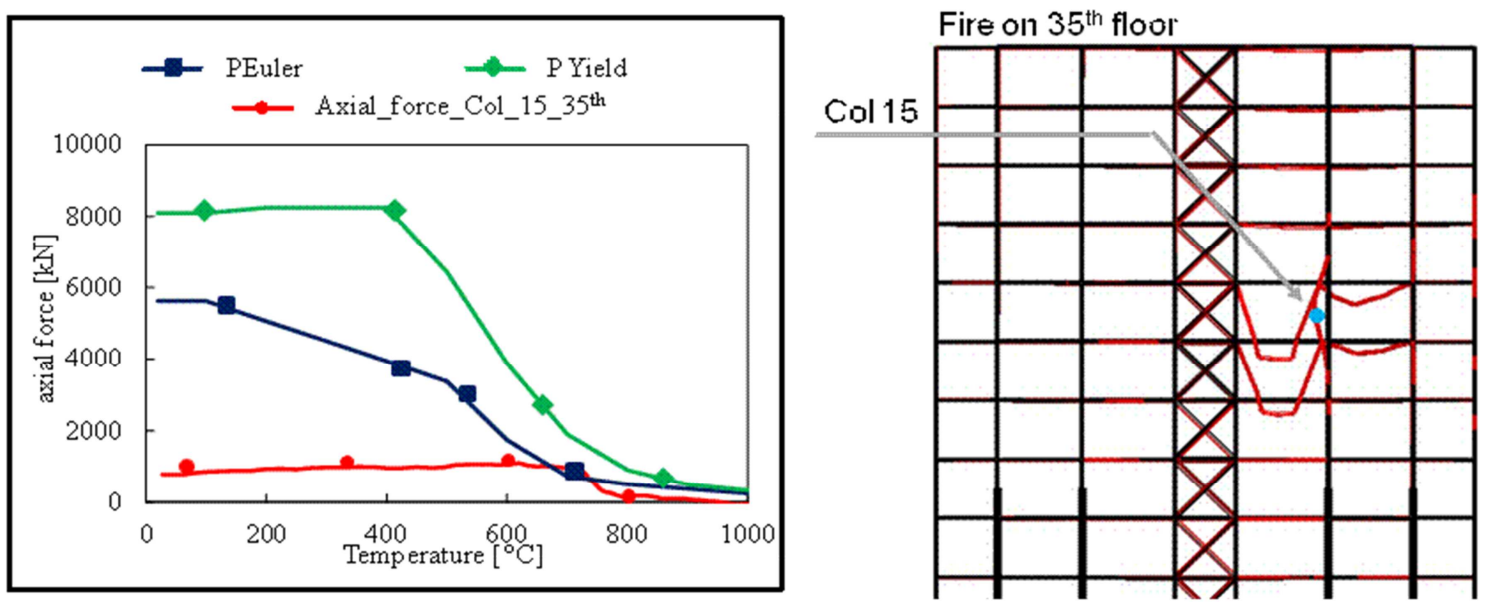

Fig. 12: Results of SM-1-35-c: deformed configurations after 50 min of fire at the $35^{\text {th }}$ floor (right); evolution of the axial force in the heated column (column 15) and buckling crisis (left);

\section{CONCLUSIONS}

In this paper the behaviour of a high rise building in fire is investigated, with the aim of highlighting basic failure mechanisms and comparing the response of the building to fires at different heights.

The assumptions taken and the problems faced in the modelling have been discussed and some significant aspects concerning the definition of collapse condition and the interpretation of the outcomes have been highlighted. With specific reference to the case study considered, some outcomes are worth of being summarised in the following:

1. The structure is characterized by a stiff column -slender beams framed system. This characteristic is responsible of a high vulnerability to fire of the floor system, where early buckling failures of beams are triggered as a consequence of the fact that the beam thermal expansion is almost completely hindered by the stiff columns.

2. To the high vulnerability of the floor system counterpoises a relative high robustness of the building as a whole, due to the fact that, as a consequence of the high critical temperature of the columns, the vertical bearing system remains stable much longer.

3. The building system seems more sensible to a fire in the upper part of the building, as shown by the comparison of the investigations carried on at the $5^{\text {th }}$ and $35^{\text {th }}$ floor: when a fire triggers at lower floor levels, where the stiffness difference between beams and columns is more pronounced, a vertical or horizontal propagation of the collapse seems unlikely, due to the very modest redistribution of stresses on the column; however, in case of a fire at higher floors, both horizontal vertical propagation of the collapse seem possible. 
From the results presented above for the considered case study, more general considerations can be derived. In particular, the failure mechanism of a steel framed beam-column system seems to be driven by:

1. the starting loading conditions of the structure

2. the raise of eigenstresses as a consequence of hindered thermal expansion

3. the possible loss of lateral restraints, which can induce a buckling failure in non slender compressed elements

It has to be noted that the consideration of the first two aspects is influenced by the current European regulations, which allow a significant reduction of the design loads in case of fire [21] and permit to neglect the effects of hindered thermal expansion in the verification of isolated elements, provided that the standard fire is used [13].

The third aspect can only be evaluated by means of an advanced investigation where the behaviour of the structure as a whole is considered and the response of the system after the first element failures is followed. This aspect is particularly meaningful in the framework of ensuring a proportionate response also in case of unexpected circumstances, such as design errors or as a consequence of arson or other critical events not explicitly considered in the usual fire design. Even if it seems sensible to accept some local damages in case of such rare and severe events, the occurrence of major structural collapse should be avoided under all circumstances, as explicitly required nowadays by most codes and regulations [22] [23].

In particular, with respect to fire-induced collapses [24], it seems important to avoid the propagation of failures to elements not directly affected by the fire, i.e. elements where the temperatures do not play a significant role in the failure.

\section{References}

[1] SFPE: "Guidelines for designing fire safety in very tall buildings", Task Group on Fire Safety in very tall buildings, Society of Fire Protection Engineer (SFPE) Public review draft, March 2012.

[2] Meacham B., Engelhardt M., Kodur V. (2009): "Collection of Data on Fire and Collapse, Faculty of Architecture Building, Delft University of Technology", Proc. of NSF Engineering Research and Innovation Conference, Honolulu, Hawaii, 2009

[3] NILIM (2005): "Report on the Windsor Building Fire in Madrid, Spain", National Institute for Land and Infrastructure Management, Japan, Jul 2005 (in Japanese).

[4] NIST NCSTAR 1 (2005): "Final Report on the Collapse of the World Trade Center Towers, , National Institute of Standards and Technology (NIST), Gaithersburg, MD, 2005.

[5] Starossek U. (2009), Progressive collapse of structures, Thomas Telford Publishing, London, 2009.

[6] Usmani A.S., Chung Y.C., Torero J.L., (2003): How Did the WTC Collapse: A New Theory, Fire Safety Journal, 38, 6, 501-591, 2003.

[7] Usmani A.S., O'Connor M.A., Rotter J.M., Elghazouli A.Y., Drysdale D.D., Sanad A.M., Gillie M. and Lamont S., (2000), Behaviour of Steel Framed Structures under Fire Conditions, DETRPIT Project final report, 2000.

[8] MSB-6 (2008): Multi-storey steel buildings - Part 6: Fire Engineering, Steel Building in Europe design manual, Research Fund for Coal and Steel of the European Community, 2008.

[9] Faber M.H., Stewart M.G., (2003), Risk assessment for civil engineering facilities: critical overview and discussion, Reliability Engineering and System Safety 80, 173-184, 2003.

[10] Nii D., Yamaguchi J., Mase R., Notake H., Ikehata Y., Tanaka T., (2010), Risk-Based Selection of Design Fire Scenarios in Performance Based Evacuation Safety Designs of Buildings, proc. of the $8^{\text {th }}$ International Conference on Performance-Based Codes and Fire Safety Design Methods, Lund University, Sweden,16-18 June, 2010.

[11] Gkoumas K., Crosti C., Bontempi F., (2008), Risk Analysis and Modelling Techniques for Structural Fire Safety, proc. of the $9^{\text {th }}$ International Conference on Computational Structures Technology, Athens, Greece, September 2-5 2008.

[12] Buchanan A. H. (2002) Structural Design for Fire Safety, Wiley, Chichester, England, 2002. 
[13] EN1993-1-2, (2005), Design of steel structures - Part 1-2: General rules - Structural fire design, Comité Européen de Normalisation (CEN), 2005.

[14] Giuliani L. (in press), Structural safety in case of extreme actions, International Journal of LifeCycle and Performances Engineering (IJLCPE), accepted for publication in the special issue on Performance and Robustness of Complex Structural Systems on November 2011.

[15] http://www.3ds.com/products/simulia/portfolio/abaqus/overview/

[16] Pettersson O., Magnusson S.E., Thor J. (1976), Fire Engineering design of steel structures. Bulletin 52 1976, Sweden

[17] BS 5588-5 (2004) Fire precautions in the design, construction and use of buildings - Part 5: Access and facilities for fire-fighting, British Standard

[18] UFC 4-023-03 (2005), Design of buildings to resist progressive collapse, Unified Facilities Criteria (UFC), 25 January 2005.

[19] NTC (2008): Norme tecniche per le costruzioni, D.M. 14 Gennaio 2008.

[20] Giuliani L., Budny I. (accepted for publication): "Different design approaches to structural fire safety", International Journal of Life-Cycle and Performance Engineering, accepted for publication in the special issue on Fire Safety Design and Robustness Considerations in Structural Engineering in December 2011

[21] EN1991-1-2 (2004), General actions - Actions on structures exposed to fire. Comité Européen de Normalisation (CEN), 2004.

[22] ASCE 7-02 (2002) Minimum design loads for buildings and other structures. American Society of Civil Engineers, 2002.

[23] EN 1991-1-7 (2006) General actions - Accidental actions. Comité Européen de Normalisation (CEN), 2006.

[24] Bontempi F, Petrini F (2010) Fire-Induced Collapses in Structures: Basis of the Analysis and Design. Proceedings of The Fourth International Conference on Structural Engineering, Mechanics and Computation (SEMC2010), Cape Town (South Africa), 6-8 September 2010. 